\title{
Reliability and usability of tourism climate indices
}

\author{
Ghislain Dubois $^{1 *}$, Jean Paul Ceron ${ }^{2}$, Clotilde Dubois ${ }^{3}$, Maria Dolores Frias ${ }^{4}$ and Sixto Herrera ${ }^{5}$
}

\begin{abstract}
Tourism climate indices (TCl) are commonly used to describe the climate conditions suitable for tourism activities, from the planning, investment or daily operations perspectives. A substantial amount of research has been carried out, in particular with respect to new indices formulae adapted to specific tourism products, and parameters and their weighting, taking into account surveys on the stated preferences of tourists, especially in terms of comfort. This paper illustrates another field of research, which seeks to better understand the different sources of uncertainty associated with indices. Indeed, slight differences in formula thresholds, variations in computation methods, and also the use of multimodel ensembles create nuances that affect the ways in which indices projections are usually presented. Firstly, we assess the impact of differences in preference surveys on the definition of indices thresholds, in particular for thermal comfort. Secondly, we compare computation methods for France, showing the need to better specify detailed data sources and their use to ensure the comparability of results. Thirdly, using multimodel ensembles for the Mediterranean basin, we assess the uncertainty inherent in long-term projections, which are used in modelling the economic impact of climate change. This paper argues in favour of a more cautious use of tourism comfort indices, with more consideration given to the robustness of data (validation, debiasing, uncertainty assessment, etc.) and users' needs, from the climate services perspective.
\end{abstract}

Keywords: Climate, Tourism, Indices, Preferences, Mediterranean, Uncertainty, Downscaling, Climate Services

\section{Background}

Tourism climate indices endeavour to express, in a single index, the complexity of tourists' climate preferences and, therefore, the conditions suitable for tourism development (Mieczkowski 1985). As such, they are a good example of climate services, being defined (National Research Council 2001) as "The provision of one or more climate products or advice in such a way as to assist decision-making by individuals or organizations". Tourism climate indices can use either observational or modelled data, they apply to all time scales, and they can be used for planning, investment or daily operations. Given the outlook on climate change, there is an even greater need for long-term indices applications, especially to estimate the economic impacts on tourism (Amelung et al. 2007; ONERC 2009; Amelung and Moreno 2012).

\footnotetext{
* Correspondence: dubois.ghislain@tec-conseil.com

${ }^{1}$ TEC, 38 rue Sénac de Meilhan, 13001 Marseille, France

Full list of author information is available at the end of the article
}

Tourism comfort indices rely on thresholds and classification that determine a range and quantitative scale for each index component.

Mieczkowski (1985) defined the most commonly used tourism comfort indice using the following formula:

$$
\begin{aligned}
\mathrm{TCI}=2 \times[(4 \times \mathrm{CID}) & +\mathrm{CIA}+(2 \times \mathrm{P}) \\
& +(2 \times \mathrm{S})+\mathrm{W}]
\end{aligned}
$$

Where $\mathrm{CID}=$ index of thermal comfort during the day $\left({ }^{\circ} \mathrm{C}\right), \mathrm{CIA}=$ daily thermal comfort index $\left({ }^{\circ} \mathrm{C}\right), \mathrm{P}=$ total monthly rainfall $(\mathrm{mm}), \mathrm{S}=$ sunshine $(\mathrm{h} /$ day) and $\mathrm{W}=$ wind speed $(\mathrm{km} / \mathrm{h})$.

Improved indices like the climate index for tourism (CIT) by De Freitas, Scott and al. (2008) start with surveys on tourists' stated preferences to define scales that better reflect tourists' perceptions of comfort (de Freitas, Scott et al. 2008). The objective here is to test the reliability of surveys as sources of thresholds, in particular for thermal comfort.

The economic implications of applying tourism comfort indices for decision making can be substantial. Therefore, 
it is important to improve indices and detail their conditions of use. This leads to two observations.

Firstly, there are growing concerns with respect to uncertainties and margins of error associated with tourism climate indices. These uncertainties result from the index's definition (weighting of parameters and choice of thresholds with reference to preference surveys) and calculation methods (detailed computation methods). This may limit the usefulness of such indices in long-term projections and climate change impact assessments. Indeed, it is still uncertain whether these margins of error, cumulated with other sources in the "uncertainty cascade" (natural climate variability, different global circulation models, different climate downscaling methods and different reference socio-economic scenarios) prevent users from drawing long-term conclusions as to the future of global tourism and the redistribution of tourism flows under climate change assumptions. Consequently, the quality, precision and uncertainty inherent in data sources used to calculate indices must be further examined so as to guide product users and producers. For instance, results may vary depending on the use of monthly, daily or tri-hourly data. Wind series, be they observed or modelled, are far less reliable than temperature series: should they be less heavily weighted? Depending on the grids produced by data sets or chosen for model results, results may not show the geography spread of climatic effects (breeze, altitude, etc.), even though tourism depends on local conditions. This paper illustrates these issues by assessing how differences in preference surveys affect the definition of tourism climate indices thresholds, in particular for thermal comfort. We then compare computation methods for France, showing the need for more precise detailed data sources and methods ensuring the comparability of results.

Secondly, using a single projection to explore the future may give decision-makers the impression that the direction of change is unique. This is not the case: several other projections exist and full uncertainty analyses could be completed using appropriate data sets. Predicting and anticipating the consequences of climate change on the attractiveness of destinations now and in the future is a real challenge for the tourism economy. Some signs of a possible redistribution of tourism flows can be evaluated by the evolution of the tourism climate indices in future climate conditions. These future climate conditions are not fully known, due to various sources of uncertainty: internal variability due to the sensitivity of models to initial conditions, imperfect modelling of physical systems (convection, ocean-atmosphere, etc.), greenhouse gas (GHG) emission reference scenarios, climate downscaling methods, etc. Even though all sources of uncertainty are not yet understood and measurable, it is important to start evaluating the uncertainty linked to projections produced by climate indices like tourism climate indices.
This is illustrated here with a multimodel ensemble Mieczkowski's indice calculation for the Mediterranean using the ENSEMBLES database.

\section{Impact of climate preference surveys on index thresholds and scales}

We compare here two surveys (Dubois et al. 2009) and (Rutty and Scott 2010) that investigated, amongst other topics, the thermal comfort of tourists. Respondents were asked what temperatures they would consider "too hot" or "too cold".

Table 1 presents selected features of the two surveys.

Results for both samples show strong discrepancies in temperature thresholds (Table 2). This is due to slight differences in the questions asked, samples, nationalities, destinations, and period of stay, which differ in both surveys.

However, even after attempts to find the best comparable basis, strong discrepancies remain. Figure 1 makes further comparisons. French respondents aged between 18 and 24 planning a trip to a coastal resort in spring or summer (a sub-sample from Dubois and Ceron ) are compared with opinions expressed by a sample of students from five Northern European countries considering a summer trip to the Mediterranean (Rutty and Scott sample). While differences are less pronounced, they, are still notable. For instance, $50 \%$ of the Dubois and Ceron sample consider $34{ }^{\circ} \mathrm{C}$ is "too hot", compared to $37^{\circ} \mathrm{C}$ for $50 \%$ of the Rutty and Scott sample. Meanwhile, $50 \%$ of the Dubois and Ceron sample consider $20{ }^{\circ} \mathrm{C}$ is "too cold" compared to $22{ }^{\circ} \mathrm{C}$ for $50 \%$ of the Rutty and Scott sample. The French sample clearly appears less tolerant of heat (despite being better physically acclimated to it) and more tolerant of cold.

\section{Mieczkowski's indice and computation formulae: France}

The objective here is to show that the evaluation of suitable tourism conditions is sensitive to slight changes in computation methods. As an example, we focus on the Mieczkowski's indice.

Table 1 Comparison between (Rutty and Scott 2010) and (Dubois et al. 2009)

\begin{tabular}{lll}
\hline $\begin{array}{l}\text { Selected } \\
\text { features }\end{array}$ & (Rutty and Scott 2010) & (Dubois et al. 2009) \\
\hline Sample & & \\
- Population & Students <30 years old & All Internet users \\
- Sample size & $N=866$ & $N=1600$ \\
$\begin{array}{l}\text { Countries } \\
\text { covered }\end{array}$ & $\begin{array}{l}\text { Austria, Germany, } \\
\text { Netherlands, Sweden, }\end{array}$ & France \\
Switzerland & \\
Travel period & North/East Mediterranean & All \\
& Year & $\begin{array}{l}\text { Mostly spring } \\
\text { Trions summer }\end{array}$ \\
\hline
\end{tabular}


Table 2 Comparison between (Rutty and Scott 2010) and (Dubois et al. 2009) for temperature thresholds

\begin{tabular}{lll}
\hline Temperature results & Too hot: over $37{ }^{\circ} \mathrm{C}$ & Too hot: over $32{ }^{\circ} \mathrm{C}$ \\
& Too cold: under $22{ }^{\circ} \mathrm{C}$ & Too cold: under $14{ }^{\circ} \mathrm{C}$ \\
\hline
\end{tabular}

The study is performed for France, using the high resolution SAFRAN database from Météo France $(8 \mathrm{~km}$ gridded climatology). Since this database does not provide information on relative humidity, required for the Mieczkowski's indice, this variable was computed using sea level pressure from the E-OBS dataset and specific humidity and 2-metre temperature from SAFRAN. The Mieczkowski's indice was calculated using three different computation methods for the period 1980 to 2009.

Method 1 used mean monthly values (as (Amelung and Viner 2006) and (Rutty and Scott 2010) do) for the period 1980 to 2009 (12 values only) for each variable included in the Mieczkowski's indice (temperature and relative humidity). In this way, one value per month was calculated, as in Mieczkowski's original paper (as the author wished to develop a worldwide index, this was the only option available at that time) (Mieczkowski 1985). These figures are labelled "Mieczkowski".

Method 2 calculated daily indices values for each day of the 1980 to 2009 period. It then computed a mean value for these daily indices to obtain a monthly indice. These figures are labelled "daily".

Method 3 calculated values for every month from 1980 to 2009 (12*30 years) using monthly values for input variables in the Mieczkowski's formula. Then we computed the monthly mean. These figures are labelled "monthly".

Results show that the values calculated for France appear similar for the three computation methods as far as annual means are concerned. However, for the winter and summer seasons, which are of high importance for tourism, Fig. 2 shows that the "daily" method appears to produce far less spatially contrasted results than the "Mieczkowski" method.

\section{An assessment of long-term uncertainty in Mieczkowski's} indice projections: using the ENSEMBLES database

Tourism comfort indices can be projected into the future so as to assess the future conditions for tourism development. This involves running calculations with indices based on various socio-economic scenarios that correspond to different levels of GHG emissions and climate change (IPCC SRES scenarios, or IPCC AR5 RCP scenarios, for example). (Rutty and Scott 2010) use a single scenario (A1B) whereas (Amelung and Viner 2006) ultimately use two: A1F as a worst-case scenario and B1A to represent slower climactic change. It can be noted that the increase of temperatures in 2100 differ by around $1.5^{\circ} \mathrm{C}$ between A1B (lower) and A1F (higher) ; thus the vision of climate change between the two papers significantly differs. Projections can also use different models, so as to take into account the uncertainty linked to the current limitations in our understanding of the climate. Note that (Amelung and Viner 2006) use a single model (HadCM3) thus capturing only part of the uncertainty in projections.

Both approaches make it possible to ascertain the uncertainty associated with a given indice figure in reference to a single model or a single scenario.

The EU-FP6 project ENSEMBLES developed an ensemble of coupled simulations associating global climate models and regional climate models (GCM-RCM). This ensemble of climate projections covers Europe and most of the Mediterranean Basin at high resolution
Too hot $\left({ }^{\circ} \mathrm{C}\right)$ above...

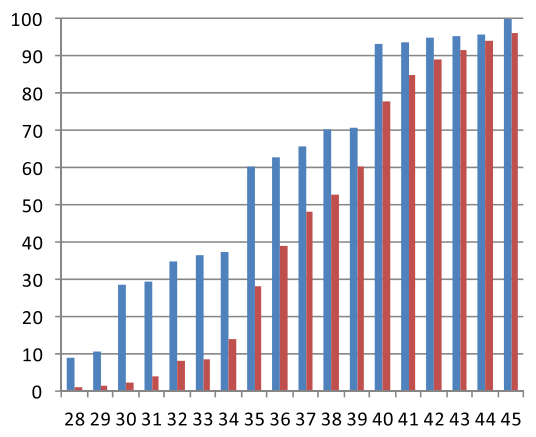

Too cold $\left({ }^{\circ} \mathrm{C}\right)$ below...

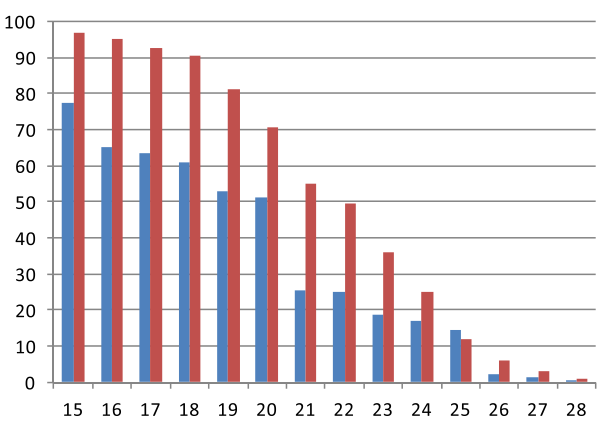

Ceron and Dubois

Rutty and Scott

Fig. 1 Share (\%) of the sample declaring a temperature as too hot (or "unacceptably hot") or too cold (or "unacceptably cold") 


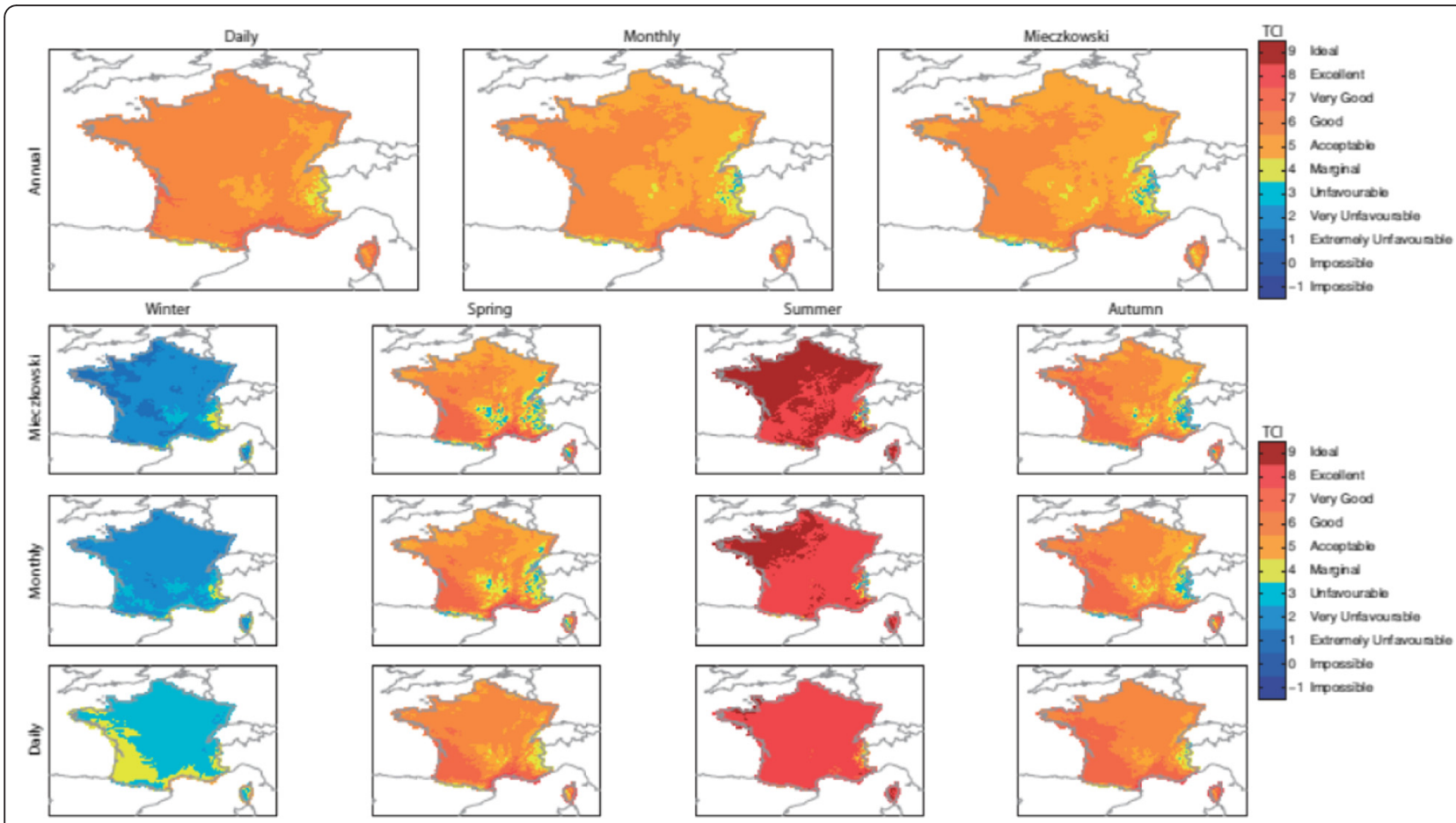

Fig. 2 Mieczkowski's tourism comfort indice for the 1980-2009 period, annual and seasonal means using three computation methods: "daily" for daily values averaged over the period, "monthly" for monthly individual values then averaged over the 1980-2009 period, "Mieczkowski" for a single calculation for the 1980-2009 period using mean monthly values of individual parameters (temperature and relative humidity). Top row: annual values; bottom rows: seasonal values. Source: University of Cantabria, SAFRAN and eOBS databases

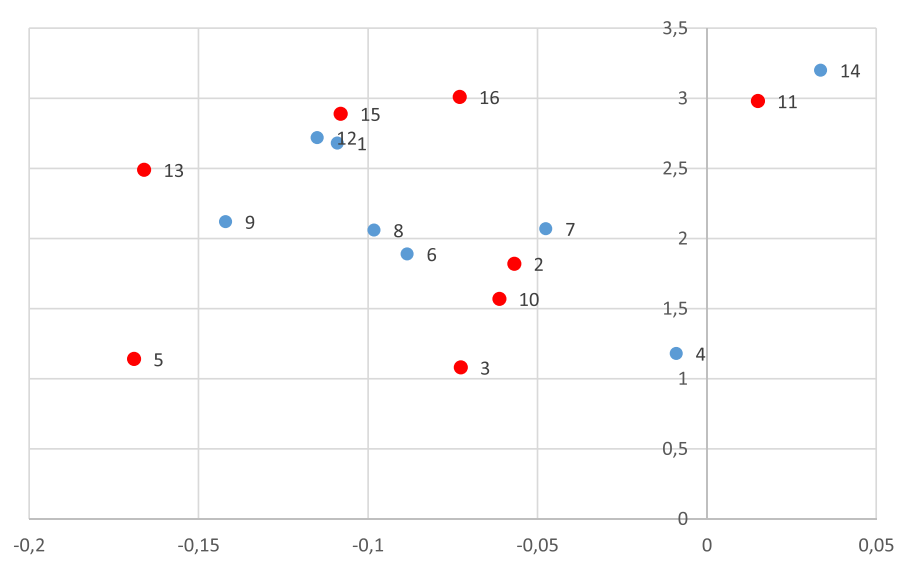
1 CNRM-RM5.1 ARP
2 DMI-HIRHAM5 ARP
3 DMI-HIRHAM5 BCM
4 METNOHIRHAMBCM
5 SMHIRCABCM
6 DMI-HIRHAM5 EH5
7 ICTP-REGCM3 EH5
8 KNMI-RACMO2 EH5
9 MPI-M-REMO EH5
10 SMHIRCA EH5
11 C4IRCA3 Had
12 ETHZ-CLM Had
13 METNOHIRHAM Had
14 METNO-HC Had
15 UCLM-PROMES Had
16 KNMI-RACMO2 MIR

Fig. 3 Change in precipitation (mm/day) and in mean air surface temperature $\left({ }^{\circ} \mathrm{C}\right)$, June-July-August, 2041-2050 vs 1970-1980, in IPCC A1B scenario. The red dots are the ENSEMBLES projections for which the variables necessary to calculate Mieczkowski's indice are available. Entire Mediterranean region $(\mathrm{LAT}=30$ 48; $\mathrm{LON}=10 \mathrm{~W}-40 \mathrm{E})$ 


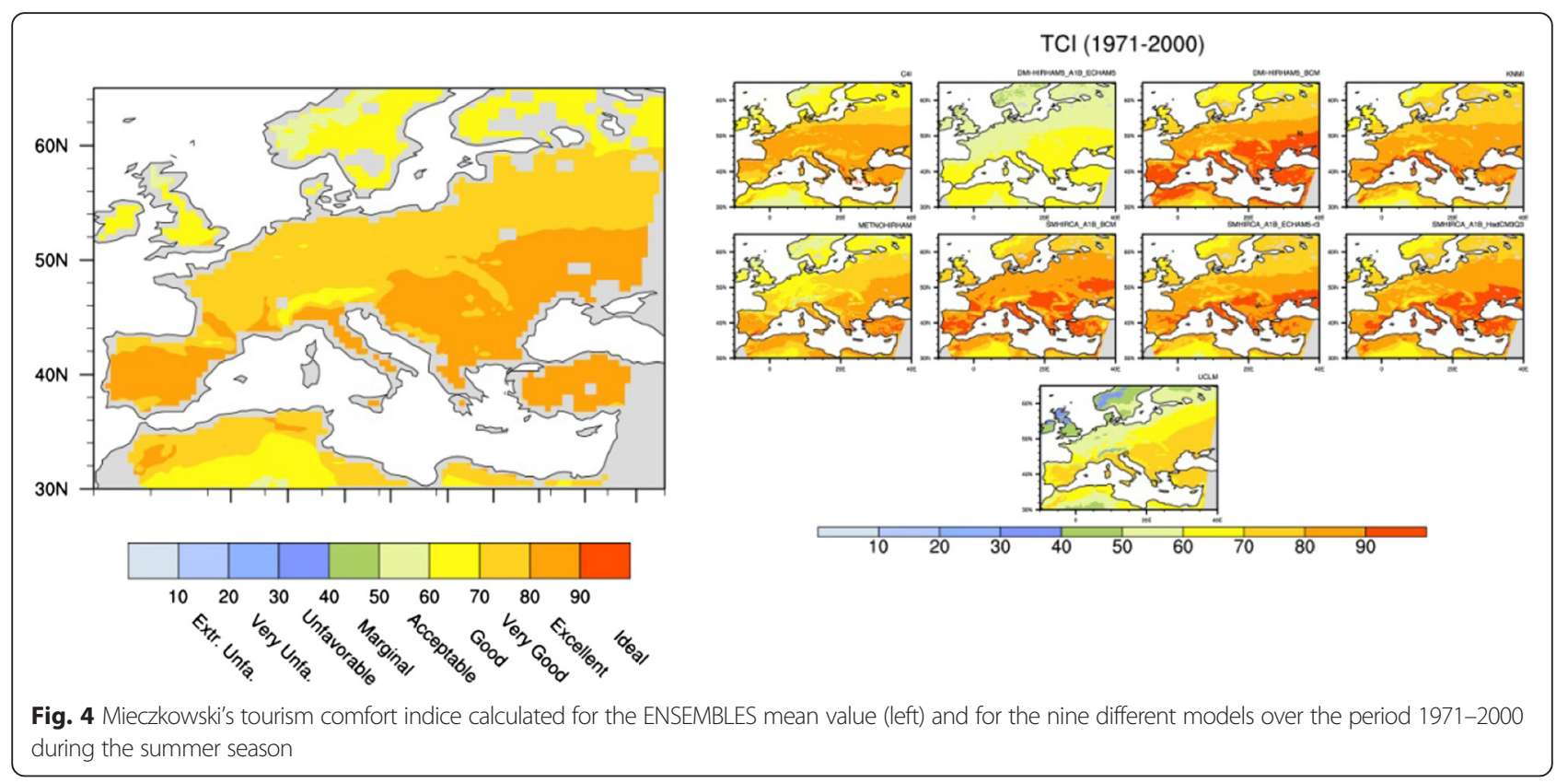

$(25 \mathrm{~km})$ for the IPCC SRES A1B scenario. These RCMs are a good representation of the present climate in a region characterized by the presence of coastal areas and a complex orography.

The Mieczkowski (1985) indice was calculated for the 9 GCM-RCM couples with the variables necessary for calculation. Figure 3 helps locate these nine projections in the broader ensemble provided by ENSEMBLES: it shows the evolution of temperatures and precipitations compared to the current situation, therefore helping to situate the GCM-RCM used in the broadest ensemble of 16 projections available.

Series were calculated for the whole year and for summer periods, for the reference period 1971-1990, for the near future period 2021-2050, and for the far future period 2071-2100.

Results show that indices values for the present period are higher over the northern part of the Mediterranean region. The northern European and Saharan regions have the lowest indices. The spatial distribution between models is relatively consistent, however there is disparity in absolute indices values. For example, one model has no Mieczkowski's value higher than 70 in the summer season.

The number of days rating over 70 ("very good" to "ideal" conditions in the Mieczkowski scale) can be calculated over the three summer months (JJA: June, July, August). The ensemble's mean points to about

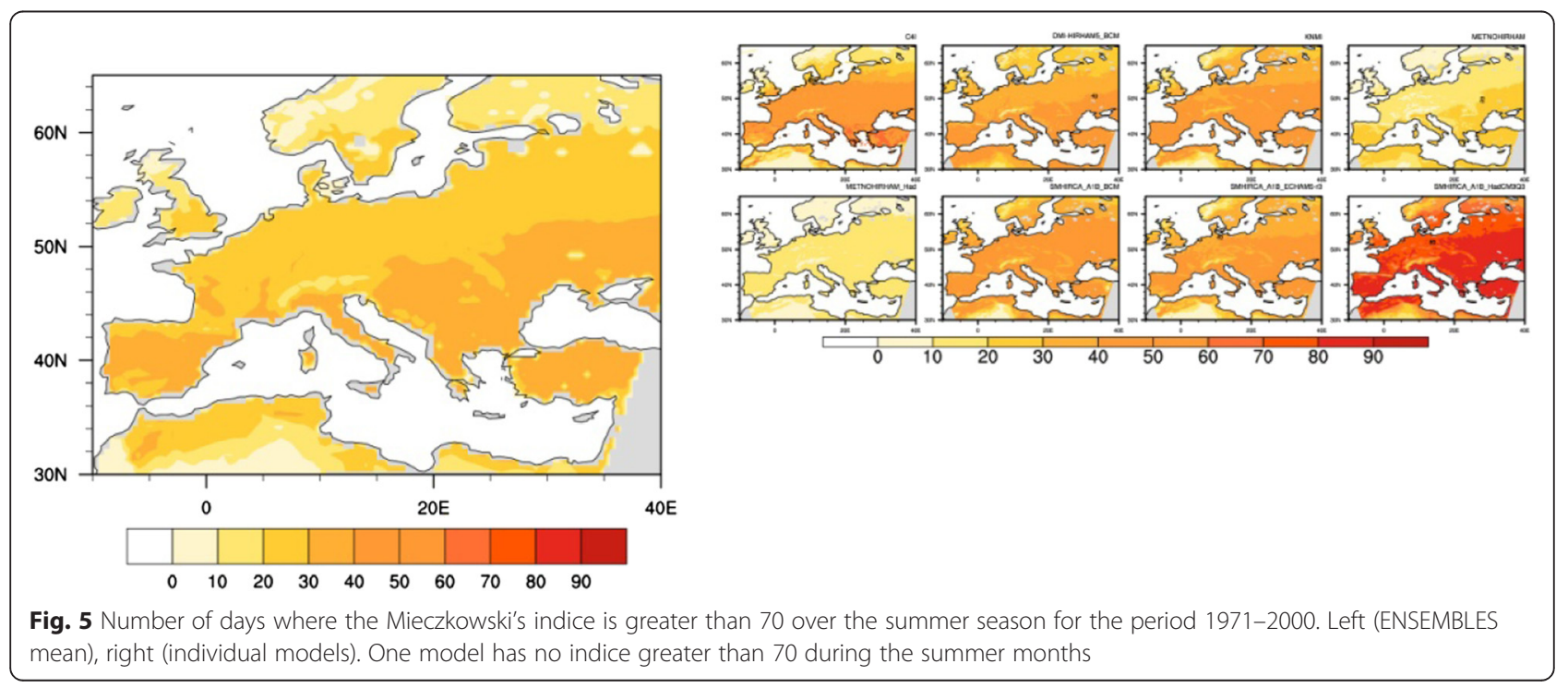




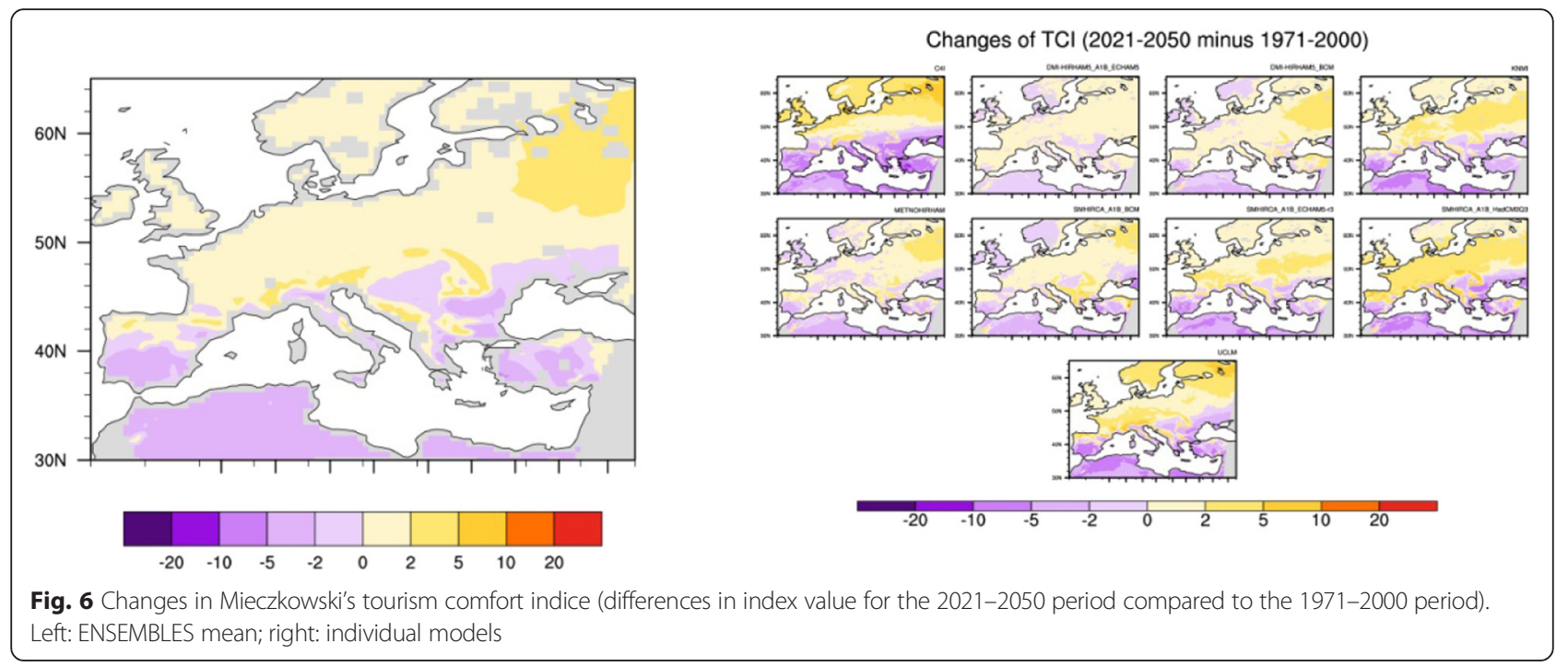

50 comfortable days during the summer in southern Europe.

The average indice value for the domain considered in JJA, for the 1971-2000 period (10 W-38E / 30-50 N) is 78 , with a value of 62 for the UCLM-PROMES projection, and up to 84 for the SMHIRCA-BCM projection. This gives a very different picture, with an average Mediterranean climate moving from "good" to "excellent" (two levels higher), according to the Mieczkowski scale. Figures 4 and 5 show some very significant local divergences between models.

With climate change, the temperature is expected to increase in the Mediterranean and precipitations are very likely to decrease. Humidity and wind will also be affected. In the near future (2021-2050 Fig. 6), the indice increases on average north of $45^{\circ} \mathrm{N}$ and decreases further south. The change in the indice is weak and does not show any gain in the number of days rating over 70 north of $45^{\circ} \mathrm{N}$. Conversely, the number of days over 70 decreases south of $45^{\circ} \mathrm{N}$ with the strongest decrease in North Africa.

The pictures created by the individual models can differ significantly from the average with respect to the direction of change. The $45^{\circ} \mathrm{N}$ limit can vary depending on models. While some projections like C4I, SMHI-RCA-ECHAM and KNMI show some contrasting movements, which are relatively consistent with the $45^{\circ} \mathrm{N}$ border, others like METNO-HC-HAD, DMI-HIRAM-ECHAM5 and SMHIRCA-BCM show less intensive and less contrasting evolutions.

Figure 7 shows similar results for the changing number of days where Mieczkowski's indice is greater than 70 in summer. While some projections predict little change, others like SMHI-RCA predict quite drastic

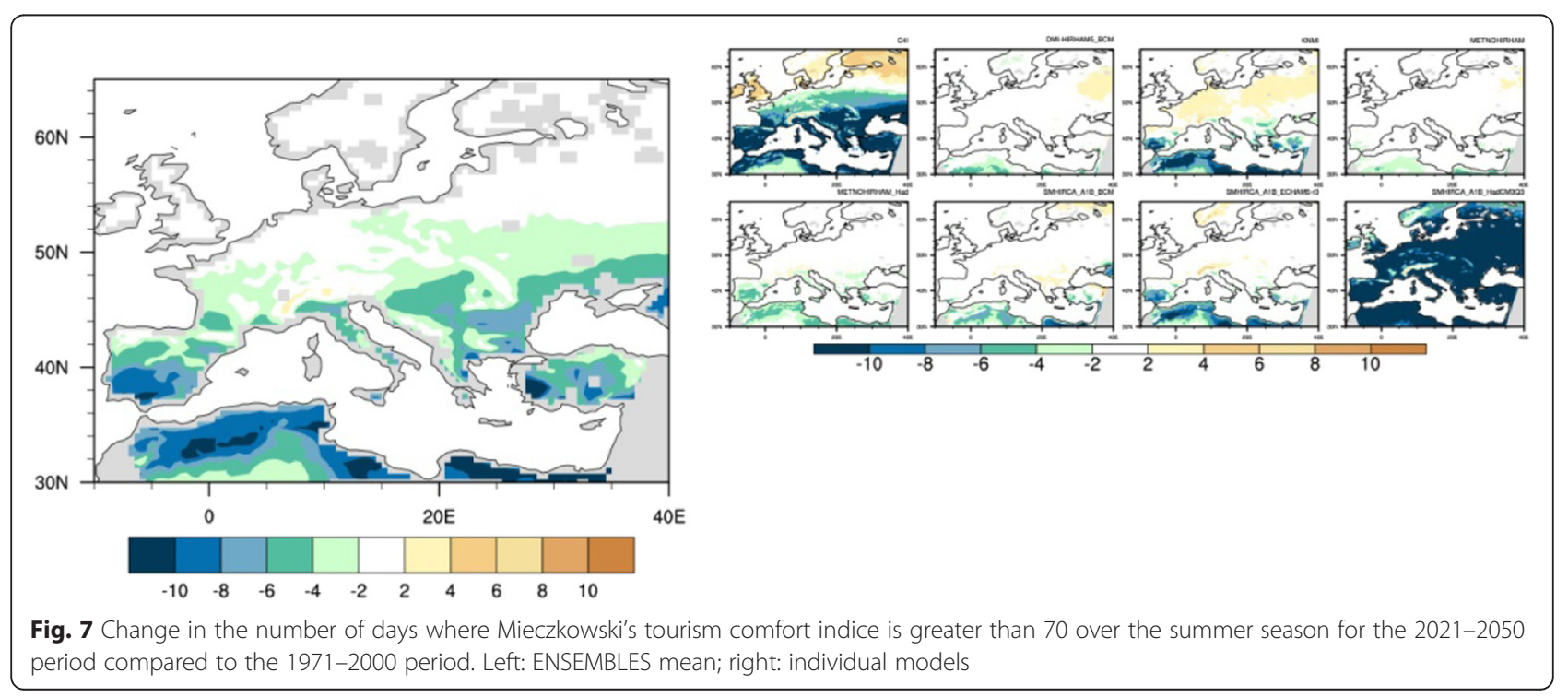



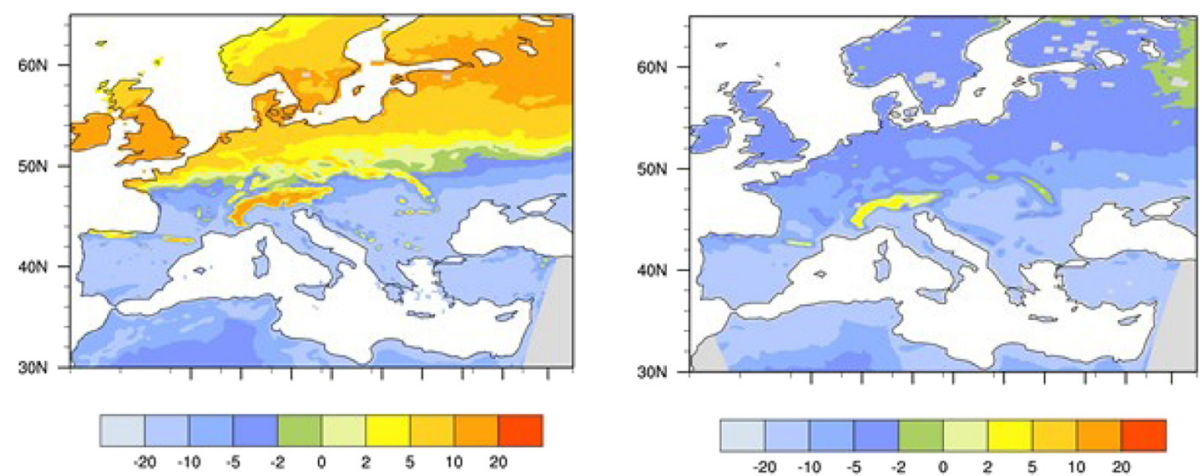

Fig. 8 Change in the Mieczkowski's indice value for the 2071-2100 period minus the index value for the 1971-2000 period. Left: C4I projection; right: KNMI projection

changes, with a decrease of more than 10 points throughout the Mediterranean Basin. The consequences for tourism are obviously very different.

Figure 8 shows two contrasted projections for the far future (2071-2100). While projections tend to converge over the Mediterranean, there are major differences in terms of the direction of change for Northern Europe.

\section{Discussion}

Our results first show the limit of comparability for existing surveys on the stated preferences of tourists. The use of such surveys to define tourism comfort indices scales is an obvious improvement. In the absence of a harmonized international survey however, integrating sparse sources in a single index remains an expert judgment. When defining the index, the weighting should not be overly heavy for components using scales and thresholds, in particular thermal comfort. This is consistent with other results showing that rainfall, and not only thermal comfort, is crucial in tourists' satisfaction (or dissatisfaction) (see (Dubois et al. 2009).

Second, we show the need to clarify recommended computation methods, so as to be able to evaluate climate potential and compare destinations in a consistent way. Yet, clarifying the calculation methods does not systematically allow to compare results if the methods, though explicit, remain different. It would help if a common standard could be agreed upon. The research community will have some difficulties reaching this in the absence of a coordinated worldwide (or at least transcontinental) project on the topic.

Third, considering the uncertainty associated to multi models ensembles helps provide a general message to stakeholders using tourism comfort indices to design climate change adaptation strategies. For example, this would help to clarify the discussion over the future of the suitability of Mediterranean climate for tourism. Over two decades several studies have been showing different or even contradicting results and sometimes pretending to invalidate the results of previous work (Carter 1991; Rotmans et al. 1994; Perry 2001; Amelung and Viner 2006; Rutty and Scott 2010). They leave it to the reader to find the reasons of such discrepancies. As a minimum, it suggests that future economic modelling must be developed with error bars. As a maximum, which is not always attainable, it means that the most robust information must be selected for investors and decision-makers requiring full uncertainty assessments for decision-making. It should also be remembered that such assessments do not consider the evolution of the other contextual features that can prove as influential as the change in the indice. For example, the growth of urbanisation which can lead to an increase in the heat island effect or conversely the adaptive capacity of people to hotter temperatures (e.g. the alert thresholds for heatwaves vary by more than $10{ }^{\circ} \mathrm{C}$ between the North and the South of France (Institut National de Veille Sanitaire 2005).

With some methodological improvements and constant quality checks, however, improved indices could be useful to improve decision-making and anticipate climate change in the tourism sector.

\section{Competing interests}

The authors declare that they have no competing interests

\section{Authors' contributions}

GD coordinated the paper and drafted the manuscript, CG drafted the Cyprus case study, CD drafted the ENSEMBLES case study, MDF and SH drafted the France case study, JPC revised the paper and drafted part of the introduction. All authors read and approved the final manuscript.

\section{Acknowledgments}

This paper was written by a team participating in the EU FP7 project CLIM-RUN "Climate Local Information in the Mediterranean region Responding Users' 
Needs" (2011-2014). The CLIM-RUN project aimed at developing a better understanding of the interaction between users and producers of climate services in order to help define Mediterranean climate service networks. CLIM-RUN developed a bottom-up protocol directly involving stakeholders early in the process with the aim of identifying well defined needs on the regional and local scales. Improved modelling and downscaling tools were then used to respond to these specific needs in an optimal way.

\section{Author details}

${ }^{1}$ TEC, 38 rue Sénac de Meilhan, 13001 Marseille, France. ${ }^{2} 5$ rue de la République, 19290 Sornac, France. ${ }^{3}$ Météo France, CNRM, Toulouse, France. ${ }^{4}$ University of Cantabria, Santander Meteorological Group, Instituto de Física de Cantabria, IFCA, Avda. de los Castros, s/n, 39005 Santander, Spain.

${ }^{5}$ Santander Meteorological Group, Instituto de Física de Cantabria, IFCA, Avda. de los Castros, s/n, 39005 Santander, Spain.

\section{Received: 30 December 2014 Accepted: 8 April 2016}

Published online: 18 April 2016

\section{References}

Amelung B, Moreno A (2012) Costing the impact of climate change on tourism in Europe. Results of the PESETA project. Clim Chang 112(1):83-100

Amelung B, Viner D (2006) Mediterranean tourism: exploring the future with the tourism climatic index. J Sustain Tour 14(4):349-366

Amelung B, Nicholls S et al (2007) Implications of global climate changefor tourism flows and seasonality. J Travel Res 45(3):285-296

Carter T (1991) The Hatch index of climate favourability. Finnish Meteorological Institute, Helsinki, p 18

de Freitas C, Scott D et al (2008) A second generation climate index for tourism (CIT): specification and verification. Int J Biometeorol 52:399-40

Dubois G, Ceron JP et al (2009) Météorologie, climat et déplacements touristiques: comportements et stratégies des touristes. MEIE/MEEDDAT/DIACT, Paris, p 93

Institut National de Veille Sanitaire (2005) Système d'alerte canicule et santé 2005. INVS, Paris, p 54

Mieczkowski Z (1985) The tourism climatic index: a method of evaluatingworld climates for tourism. Le géographe canadien XXIX 3:220-233

National Research Council (2001) A climate service vision. First steps towards the future. National Academy Press, Washington

ONERC (2009) Changement climatique: coûts des impacts et pistes d'adaptation. Raport au Premier ministreet au Parlement. La Documentation française, Paris

Perry A (2001) More heat and drought - Can Mediterranean tourism survive and prosper? proceedings of the 1st international workshop on climate, tourism and recreation., international society of biometeorology, commission on climate tourism and recreation

Rotmans J, Hulme M et al (1994) Climate change implications for Europe. Glob Environ Chang 4:97-124

Rutty M, Scott D (2010) Will the Mediterranean become" too hot" for tourism. A reassessment. Tourism Hospitality Planning and Development 7(3):267-281

\section{Submit your manuscript to a SpringerOpen ${ }^{\circ}$ journal and benefit from:}

- Convenient online submission

- Rigorous peer review

- Immediate publication on acceptance

- Open access: articles freely available online

- High visibility within the field

Retaining the copyright to your article 